\title{
Spawning induction, development and culturing of the solitary ascidian Polycarpa mytiligera, an emerging model for regeneration studies
}

Tal Gordon ${ }^{1 *}$ (D) Lachan Roth ${ }^{1}$, Federico Caicci ${ }^{2}$, Lucia Manni ${ }^{2^{* \dagger}}$ and Noa Shenkar ${ }^{1,3+}$

\begin{abstract}
Background: Ascidians (phylum Chordata, class Ascidiacea) represent the closest living invertebrate relatives of the vertebrates and constitute an important model for studying the evolution of chordate development. The solitary ascidian Polycarpa mytiligera exhibits a robust regeneration ability, unique among solitary chordates, thus offering a promising new model for regeneration studies. Understanding its reproductive development and establishing landbased culturing methods is pivotal for utilizing this species for experimental studies. Its reproduction cycle, spawning behavior, and developmental processes were therefore studied in both the field and the lab, and methods were developed for its culture in both open and closed water systems.

Results: Field surveys revealed that $P$. mytiligera's natural recruitment period starts in summer (June) and ends in winter (December) when seawater temperature decreases. Laboratory experiments revealed that low temperature $\left(21^{\circ} \mathrm{C}\right)$ has a negative effect on its fertilization and development. Although spontaneous spawning events occur only between June and December, we were able to induce spawning under controlled conditions year-round by means of gradual changes in the environmental conditions. Spawning events, followed by larval development and metamorphosis, took place in ascidians maintained in either artificial or natural seawater facilities. P. mytiligera's fast developmental process indicated its resemblance to other oviparous species, with the larvae initiating settlement and metamorphosis at about $12 \mathrm{~h}$ post-hatching, and reaching the juvenile stage 3 days later.
\end{abstract}

Conclusions: Polycarpa mytiligera can be induced to spawn in captivity year-round, independent of the natural reproduction season. The significant advantages of $P$. mytiligera as a model system for regenerative studies, combined with the detailed developmental data and culturing methods presented here, will contribute to future research addressing developmental and evolutionary questions, and promote the use of this species as an applicable model system for experimental studies.

Keywords: Tunicates, Model systems, Development, Reproduction, Spawning, Polycarpa mytiligera, Red Sea

\footnotetext{
* Correspondence: talgordon@mail.tau.ac.il; lucia.manni@bio.unipd.it

'Lucia Manni and Noa Shenkar contributed equally to this work.

'George S. Wise Faculty of Life Sciences, School of Zoology, Tel-Aviv

University, 6997801 Tel-Aviv, Israel

${ }^{2}$ Department of Biology, University of Padova, 35121 Padova, Italy

Full list of author information is available at the end of the article
}

(c) The Author(s). 2020 Open Access This article is licensed under a Creative Commons Attribution 4.0 International License, which permits use, sharing, adaptation, distribution and reproduction in any medium or format, as long as you give appropriate credit to the original author(s) and the source, provide a link to the Creative Commons licence, and indicate if changes were made. The images or other third party material in this article are included in the article's Creative Commons licence, unless indicated otherwise in a credit line to the material. If material is not included in the article's Creative Commons licence and your intended use is not permitted by statutory regulation or exceeds the permitted use, you will need to obtain permission directly from the copyright holder. To view a copy of this licence, visit http://creativecommons.org/licenses/by/4.0/. The Creative Commons Public Domain Dedication waiver (http://creativecommons.org/publicdomain/zero/1.0/) applies to the data made available in this article, unless otherwise stated in a credit line to the data. 


\section{Background}

Ascidians are marine invertebrates that constitute the closest relatives to the vertebrate subphylum $[1,2]$. They are primarily sessile, with a brief pelagic larval stage that shares the typical chordate tadpole-type features, including a pharynx with gill slits, a notochord, and a hollow nerve cord [3]. Due to their phylogenetic position, inland culturing methods, relatively short life cycle, and simple body plan, ascidians offer an important model for developmental and evolutionary studies [4-7]. Furthermore, their high regenerative abilities make them a key model system for studies seeking to understand the evolution of vertebrate regeneration [8-10].

While many ascidian species are used for cellular and molecular studies, including gene function and regulation during development [7, 10-13], a culturing technique has been established for only a few solitary species, such as Ciona robusta (previously called $C$. intestinalis type A [14]), Ciona intestinalis and Halocynthia roretzi $[5,15-17]$. The extensive study of these latter species has led to the development of genetic tools and molecular approaches, including stable transgenic lines $[5,12,15]$. The ability to easily and efficiently breed and maintain a research organism under laboratory conditions is crucial for determining its feasibility to serve as a model system.

The current study focused on the solitary ascidian Polycarpa mytiligera (Order: Stolidobranchia). This species is the most common solitary ascidian in the Gulf of Aqaba, Red Sea [18], and an emerging model system for regenerative studies due to its high regenerative abilities [19-21]. These abilities, described also in other Polycarpa species, have led researchers in the past to suggest the occurrence of asexual reproduction in this genus [22-24]. However, all the studied Polycarpa species to date present a strictly sexual reproduction strategy [25-27].

All ascidians, colonial and solitary, share a similar basic body plan. The adult body consists of a branchial basket, which serves for both the capture of food particles and respiration. The branchial basket opens to the exterior through two anterior siphons and is connected to the posterior digestive track [23]. The neural complex is located between the siphons and comprises a single cerebral ganglion with an associated glandular organ called the neural gland $[28,29]$. The ascidian body plan can develop through two very different pathways, sexual or asexual. This diversity of life-history strategies provides a unique opportunity for comparative developmental studies.

Ascidians are hermaphrodites, possessing both male and female organs. Solitary ascidians, such as P. mytiligera, release their gametes into the seawater by spawning, and the gametes are then fertilized externally [30,
31]. Spawning events demonstrate species specificity and are affected by different environmental cues, such as light, food availability, and regional variations in water temperature [32-35]. Following fertilization, swimming tadpole-like larvae develop. The larvae have an important role in dispersal and settlement. In free-spawning species they can swim for between $12 \mathrm{~h}$ to several days [36-38].

Ascidian larval recruitment varies among seasons, influenced by the ecological conditions and the speciesspecific interactions with the environment [39-41]. Following settlement, the larvae undergo metamorphosis, a complex process that involves various morphogenetic and physiological changes in the animal [42, 43]. Upon onset of metamorphosis, the larva attaches to the substrate via its anterior adhesive papillae [42], followed by tail resorption, which involves the loss of the notochord, hollow dorsal nerve cord, and the post-anal tail. A rotation of the body axis then begins, followed by the opening of the siphons, beating of the heart, and the appearance of blood cells, indicating that the animal has entered the juvenile stage [44]. At this stage, the growth of adult organs such as the gonads, and the continuing development of the branchial basket and digestive system, occur $[44,45]$.

Here we have developed a protocol for the spawning and culturing of $P$. mytiligera in captivity, based on field observations and controlled laboratory experiments. Using light and confocal microscopy, histology, and immunocytochemistry methods we provide the first detailed description of its early life stages, from a swimming larva to a metamorphosed juvenile. In addition to contributing to knowledge of the development, larval morphology, and metamorphosis in ascidians, this work presents a fundamental step toward establishing $P$. mytiligera as a new and valuable model system for developmental and regenerative studies.

\section{Methods}

\section{Field surveys}

Quantitative surveys were used to document P. mytiligera recruitment patterns along the north shore of the Gulf of Aqaba, Red Sea (Eilat, Israel).

Belt transects $[46,47]$ were deployed from a random start point, at $15 \mathrm{~m}$ and $5 \mathrm{~m}$ depth, along the InterUniversity Institute (IUI) south shore $\left(29.501435^{\prime \prime} \mathrm{N}\right.$, 34.917521 "E). Following selection of the start point, four belt transects $(15 \mathrm{~m} \times 1 \mathrm{~m})$, were permanently marked at $10 \mathrm{~m}$ intervals. The transects were monitored by SCUBA surveys on a monthly base for an 18-month period, from April 2015 to September 2016. During the surveys the number of $P$. mytiligera individuals was noted and their size was measured. 


\section{Animal collection for spawning experiments}

P. mytiligera spawning and reproduction were studied in two aquarium systems: an open water system connected to the Red Sea at the Inter-University Institute (IUI) in Eilat, Israel (Fig. 1a); and a closed water system located at Tel Aviv University, Tel Aviv (Fig. 1b). Adult animals were randomly collected by SCUBA diving from the north shore of the Gulf of Aqaba, Red Sea (29.547440"N, 34.954084"E). The collected animals were transferred to a water table with running seawater $(\sim 80 \mathrm{GPH})$ at the IUI, and kept under ambient conditions for $24 \mathrm{~h}$ of acclimation prior to beginning the experiments. For experiments in the closed water system at Tel Aviv University (Tel Aviv, Israel), live animals were transferred in a sealed box filled with seawater. Temperature was maintained using a cooler box. Animals were kept for $24 \mathrm{~h}$ of acclimation at a Tel Aviv aquarium facility prior to beginning the experiment. All animals were of similar size range $(5 \pm 1 \mathrm{~cm}$ in length measured from the tip of the oral siphon to the base of the animal).

\section{Open water system}

We set up an outdoor open water system at the IUI (system A) and an indoor open water system at the National Center for Mariculture in Eilat, Israel (system B). Each system comprised nine aquaria $\left(30 \times 23 \times 30 \mathrm{~cm}^{3}\right)$ supplied with fresh seawater.

The outdoor system (system A) maintained a natural seasonal day-night routine (Additional file 1). A shading net was used to reduce light intensity in order to resemble that at the collection site. This system was used for experiments simulating natural environmental conditions (i.e water temperature and day-night cycle).

The indoor system (system B) enabled control of the artificial environmental conditions (light intensity and day-night routine) by means of a set of neon lamps (18 W/865, Osram) located above the system.

In both systems seawater entering and exiting the aquariums was filtered through a $100 \mu \mathrm{m}$ mesh, preventing large particles from entering or exiting the system. Air was supplied via a stone diffuser in all aquaria. Water temperature was set using heaters or chillers according to the desired treatment in both systems.

\section{Experimental design}

Due to $P$. mytiligera's gonadal structure, direct collection of sperm and eggs from dissected animals is a complex process with a low fertilization success rate (T. Gordon, unpublished data). Gametes were therefore collected via the natural spawning process. The ascidians' tunics were carefully cleansed of epibionts and the animals were

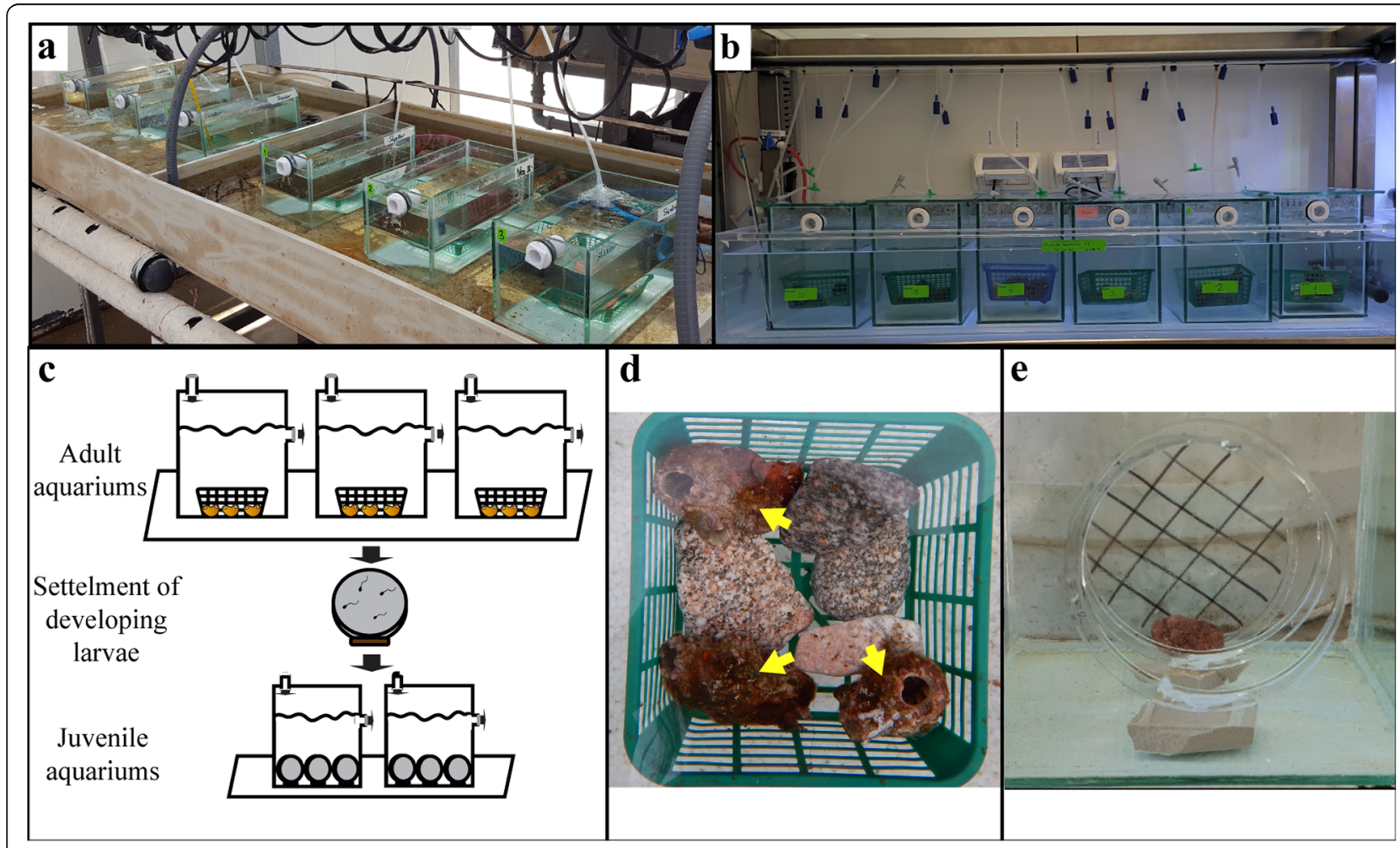

Fig. 1 Experimental design. a The open water system (System A). b The closed water system. c Illustration of the experimental design. d Adult ascidians (yellow arrows) in the aquarium system. e Petri dishes with settled larvae held vertical in the juvenile aquarium 
placed in the experimental aquarium system. Each aquarium held three individuals anchored to the bottom of the aquarium by small rocks (Fig. 1c, d). We chose to use only three animals per aquarium, which is the minimum required for natural external fertilization, in order to minimize impact on the natural population. Each aquarium is referred to as one repetition in the different experiments. The animals were observed daily to monitor their viability. Feeding was provided by the natural small food particles entering the system via the water current. To evaluate spawning success, $25 \%$ of the water volume in each aquarium was filtered, using a $65 \mu \mathrm{m}$ net, transferred to a sterile Petri dish, and scanned for reproduction products. Eggs and the post-hatching stages including swimming larvae, settled larva, and metamorphosed juveniles were collected from the water column and aquarium walls. Reproduction products in the Petri dishes were carefully counted under a microscope (Nikon SMZ18) and transferred for settlement (section 2.5). No discrimination was made between fertilized and unfertilized eggs at this stage, and a successful spawning event was determined according to the presence of live post-hatching stages in the aquaria.

\section{Temperature effect on spawning during the natural reproduction season}

The effect of seasonal variation in water temperature on spawning success, larval hatching, and metamorphosis was examined during the natural reproduction season (August 2016), under different temperature treatments. Aquarium system A was divided into three treatments: high temperature $\left(30^{\circ} \mathrm{C}\right)$, cold temperature $\left(21^{\circ} \mathrm{C}\right)$, and control with ambient temperature $\left(27^{\circ} \mathrm{C}\right)$. The selected high and low temperatures were based on the maximum and minimum temperature in the Gulf of Aqaba [48]. Three aquaria (total of nine individuals) were used for each of the treatments and the aquaria were scanned for reproduction products daily for 6 days, a time period in which the main spawning event took place (T. Gordon, personal observations).

\section{Spawning induction - effect of seasonal variation and heat shock}

To examine the effect of seasonal variation on spawning success in captivity, spawning was observed under natural conditions versus experimental conditions throughout the year in the outdoor system (system A). The environmental conditions in system A were set according to the natural conditions at the collection site (Additional file 1). As increased temperature is often used to induce spawning when culturing marine invertebrates [49-51], the effect of a thermal shock of $30^{\circ} \mathrm{C}$, two degrees above the maximum temperature in their natural habitat [48], was examined as a potential cue for inducing spawning in $P$. mytiligera.
System A was divided into two treatments: a) heat treatment, in which the animals experienced a thermal shock; and b) control treatment, maintaining the natural conditions according to the current season. Sample size and environmental conditions in system A throughout the different seasons are provided in Additional file 1.

The animals spent no longer than three full day-night cycles at the elevated temperature in order to avoid a cumulative stress reaction [52, 53]. All aquaria were scanned for reproduction products daily for 6 days following the heat treatment.

\section{Spawning induction outside the natural reproduction season}

To enable year-round spawning, we applied a gradual change from winter $\left(21-22^{\circ} \mathrm{C}\right) /$ spring $\left(22-23^{\circ} \mathrm{C}\right)$ conditions to summer conditions $\left(27-28^{\circ} \mathrm{C}\right)$ in aquarium system B. In February 2018 and April 2019, indoor aquarium system B was divided into two treatments: a) control - three aquaria maintaining the natural winter/ spring conditions; and b) heat treatment - three aquaria experiencing a gradual shift in water temperature and day length. A total of nine individuals were used per treatment. Starting conditions for both treatments were according to the natural season conditions (Additional file 1). The control treatment maintained these starting conditions for the entire experimental period, while the treatment aquaria received an increase of $1{ }^{\circ} \mathrm{C}$ every 2 days and elongation of day length by 15 min every 2 days, until reaching ambient summer conditions (27$28^{\circ} \mathrm{C}$, see Additional file 1 ).

\section{Closed water system}

A closed aquarium seawater system was set up in the aquarium facility at Tel Aviv University in order to study $P$. mytiligera reproduction success. The system comprised six aquaria $\left(15 \times 28 \times 20 \mathrm{~cm}^{3}\right)$ filled with artificial seawater (ASW). Air was supplied via a stone diffuser in all aquaria and the temperature was set using electric water heaters or chillers. A set of lamps (LED Submersible lamp, RGB 1350 mm, AQUADECOR) located above the aquarium system was used to set a day-night routine.

ASW was kept in a $270 \mathrm{~L}$ reservoir tank, connected to a second, $35 \mathrm{~L}$ tank, in which the ASW was prepared and filtered. The ASW tank was connected to a pump system mixing deionized water with salt crystals (Red Sea Salt, Red Sea), in order to achieve a final ASW salt concentration of $40 \mathrm{~g} / \mathrm{L}$ presenting a similar chemical composition to that of the Red Sea natural seawater. The ASW was pre-filtered using a protein skimmer and UV light before entering the aquarium system. Water temperature in the system was maintained by a heater at $27^{\circ} \mathrm{C}$. 


\section{Reproduction study in the closed water system}

Acclimation, cleaning, and viability examination of the adult animals were performed as described previously for the open water system. Animals $(n=12)$ were divided into six aquaria. Each aquarium held two individuals anchored to the bottom by small rocks (Fig. 1c, d). We chose to use only two animals per aquarium based on preliminary experimental results showing a low survival of adults at a higher density in a closed system (T. Gordon, unpublished results). Animals were fed daily with a live unicellular algal mix (Hymenomonas sp., Isochrysis $s p$. and Cheaetoceros $s p$. obtained from the National Center for Mariculture in Eilat, Israel) of $2 \times 10^{7}$ cells/ $\mathrm{ml}$. Evaluation of spawning success was carried out similarly to that in the open water system. A quarter of the volume for each aquarium was replaced every other day with fresh ASW to prevent the accumulation of ammonia waste and to examine the water for reproduction products. To evaluate spawning success, a water sample from each aquarium was filtered, using a $65 \mu \mathrm{m}$ net, transferred to a sterile Petri dish, and scanned for reproduction products. These products were carefully counted under a microscope (Nikon SMZ18) and transferred for settlement (section 2.5). Water temperature $\left(27-28^{\circ} \mathrm{C}\right.$ ) and day length were set to resemble the natural summer conditions in the Red Sea (Additional file 1). The aquaria were scanned for reproduction products every 2 days for a fiveweek period.

\section{Juvenile settlement and development in the open and closed systems}

Following a spawning event, the reproduction products were counted, and the live products were carefully transferred using a glass pipette to new Petri dishes with filtered seawater (in the open water system) or to ASW (in the closed system). Up to 25 live products were transferred to each Petri dish and positioned horizontally for $24 \mathrm{~h}$ to allow settlement (Fig. 1c). Dead products were identified according to the deformation of body form and were omitted from the live product count. Following settlement, the Petri dishes were deployed vertically (by anchoring them with a small stone) in the aquarium $\left(15 \times 15 \times 15 \mathrm{~cm}^{3}\right)$ (Fig. 1c, e). The natural gravity of vertical orientation kept the juveniles free from the accumulation of sediment and debris. In the open system the aquaria received a constant supply of filtered seawater $(100 \mu \mathrm{m}$ filter $)$ to create a constant water turnover (Fig. 1a). In the closed water system, the aquaria were filled with ASW, which was changed daily. The water in the aquaria was constantly aerated through a stone diffuser (Fig. 1b). Water temperature was maintained at $25 \pm$ $1{ }^{\circ} \mathrm{C}$, and the aquaria and Petri dishes with settled juveniles were kept clean by means of daily water exchange and the careful removal of particles from the Petri dishes using a paintbrush.

The survival and developmental process of the transferred reproduction products were followed and documented daily.

\section{Histology}

In order to describe the $P$. mytiligera gonadal structure, three random adults of similar size range $(5 \pm 1 \mathrm{~cm}$, from the tip of the oral siphon to the base of the animal) were collected during the summer (August 2018). The animals were fixed in $4 \%$ formaldehyde in seawater after relaxation with menthol, separated from their tunic, and dehydrated with ethanol at increasing concentrations prior to embedding in paraffin (Paraplast Plus, Lecia). Sections $(7 \mu \mathrm{m})$ were mounted on glass slides, deparaffinized, and stained with standard hematoxylin and eosin solutions. For a detailed description of $P$. mytilgera early life stages morphology, selected larvae and juveniles (1 week old) were fixed in 1.5\% glutaraldehyde buffered with $0.2 \mathrm{M}$ sodium cacodylate, $\mathrm{pH} 7.4$, plus $1.6 \% \mathrm{NaCl}$. After washing in buffer and post-fixation in $1 \% \mathrm{OsO}_{4}$ in $0.2 \mathrm{M}$ cacodylate buffer, the specimens were dehydrated and embedded in epoxy resin (Sigma-Aldrich). Sections $(1 \mu \mathrm{m})$ were counterstained with toluidine blue for morphological analysis.

\section{Immunolabeling of $P$. mytiligera early life stages}

For immunolabeling, P. mytiligera larvae $(n=10)$ and juveniles ( 1 week old, $n=10$ ) were fixed in $4 \%$ paraformaldehyde in phosphate buffered saline (PBS) overnight at $4{ }^{\circ} \mathrm{C}$, and washed three times (5 min each) in PBS followed by a $10 \mathrm{~min}$ wash in TritonX-100 at room temperature (RT). Samples were washed twice $(10 \mathrm{~min}$ each) in PBT (PBS $+0.2 \%$ Tween 20$)$ and blocked in PBT $+3 \%$ BSA for $3 \mathrm{~h}$ at RT. Antibodies were then added directly to the blocking solution overnight at $4{ }^{\circ} \mathrm{C}$. To visualize nerves and cilia, we used a mouse monoclonal anti-acetylated tubulin antibody (Sigma T7451) diluted 1:1000 in blocking solution [54-57]. Samples were then washed twice for 10 min each in PBT. Secondary antibodies (ThermoFisher, Alexa Fluor goat anti-mouse IgG 488 A-11001) and phalloidin (ThermoFisher, Alexa Fluor A-2228) were added at 1:500 dilution to the blocking solution for $3 \mathrm{~h}$ at RT. Samples were then washed in PBS three times for 10 min each. Samples were stained with Hoechst (ThermoFisher 33, 342) $(1 \mu \mathrm{g} / \mathrm{mL}$ in PBS), and mounted in VECTASHIELD (Vector Laboratories RK-93952-28) using coverslips. The negative control samples were processed without incubation in primary antibodies. No detectable fluorescence was exhibited by the specimens in the control experiments. Samples were imaged on a Leica SP5 with 10X, 20X and 40X objectives. 


\section{Statistical analysis}

Statistical analysis was performed using R statistics ( R Core Team, 2014) with RStudio (RStudio Team, 2012). Significant values for all tests were regarded as $P$ value $<0.05$.

Permutation analysis of variance (ANOVA) was applied to test for differences in $P$. mytiligera population density and individual size along the different seasons. Variation in the proportion of newly recruited individuals in the field was determined by permutation ANOVA following arcsine square root transformation.

To determine whether the amount and type of reproduction products produced during the experiment period are affected by temperature and day length, we used a permutation ANOVA, with temperature, day, and product type, as well as their interaction, as factors.

All permutational ANOVA tests were performed using the RVAideMemoire package and calculated $P$ values using 9999 random permutations [58] followed by pair-wise permutations tests for determining within-factor differences. Pairwise comparison values were corrected using the Benjamini \& Hochberg (FDR) false-discovery rate control, setting an error rate of $p=0.05$ [59].

\section{Results}

\section{Field surveys}

Field surveys were conducted in order to document the effect of seasonal variation on $P$. mytiligera's natural population recruitment pattern. The seasonal changes in chlorophyll- a concentration and seawater temperature during the survey period are illustrated in Fig. 2a-b (data summarized from the National Monitoring Program reports [48] which provide environmental data from 2004). A significantly higher number of newly-recruited individuals $(\leq 3 \mathrm{~cm})$ was found during the summer of 2015 in comparison to the winter and spring (permutational ANOVA, $p<$ $0.05, n=24$ transects per season) (Fig. 2c). Size distribution results revealed the presence of significantly larger individuals (permutational ANOVA, $p<0.05$ ) during the spring $(n=158)$ in comparison to autumn $(n=$ 104), summer $(n=168)$, and winter $(n=157)$ (Fig. 2c, d). A comparison of number of $P$. mytiligera individuals among seasons revealed significantly higher numbers in the summer, winter, and spring than in the autumn (permutational ANOVA, $p<0.05, n=24$ transects per season) (Additional file 2).

\section{Spawning success in the open-water system}

$P$. mytiligera's ability to spawn under laboratory conditions was studied in order to develop a protocol for the maintenance and culturing of this species in captivity. Ascidians maintained in captivity were shown to spawn in both the outdoor and indoor systems. Fertilized eggs were found in the aquaria only at sunset. Larvae, in various stages of metamorphosis, were found the following morning. The swimming larvae that were transferred to Petri dishes initiated metamorphosis and successfully developed into the juvenile stage.

\section{Temperature effect on spawning during the natural reproduction season}

Different temperature treatments were used to examine the effect of temperature on spawning success and development during $P$. mytiligera's natural reproduction season. Spawning events were documented in all treatments ( $n=3$ aquaria per treatment): low $\left(21^{\circ} \mathrm{C}\right)$, control $\left(27^{\circ} \mathrm{C}\right)$, and high temperature $\left(30^{\circ} \mathrm{C}\right)$. The average number of eggs in the low temperature treatment was significantly higher (permutational ANOVA, $p<0.05$ ) compared to the number of post-hatching stages (larva and juvenile) of the same treatment; and also higher than the number of eggs in the control and hightemperature treatments (Fig. 3).

\section{Spawning induction- effect of seasonal variation and heat shock}

To examine the effect of seasonal variation on spawning success in captivity, spawning events were monitored throughout the year. Spawning under both natural and thermal shock conditions (Additional file 1) were documented in the summer and autumn but not in the spring and winter. During the summer and autumn seasons about $80-100$ reproduction products per aquarium (eggs, larvae, and juveniles) were observed in both the control and high temperature treatments.

\section{Induced spawning outside the natural reproduction season}

To enable year-round spawning, we studied the effect of gradual environmental change on $P$. mytiligera's spawning success. A gradual shift in water temperature and day length from winter/spring conditions to summer conditions led to spawning events in all of the treatment aquaria ( $n=3$ aquaria). No spawning events were seen in the three control aquaria maintaining the natural winter/spring conditions. Reproduction products (ca. 40-50 per aquarium) were observed in all the treatment aquaria after 25-35 days under controlled summer conditions.

\section{Spawning success in the closed-water system}

To evaluate $P$. mytiligera's adaptation to the ASW-based facility, its survivability and reproduction success were studied. Successful spawning was displayed by the ascidians maintained in the ASW-based facility at Tel-Aviv University ( $n=6$ aquaria). During the 5 weeks of the experiment several spawning events occurred in the closed 


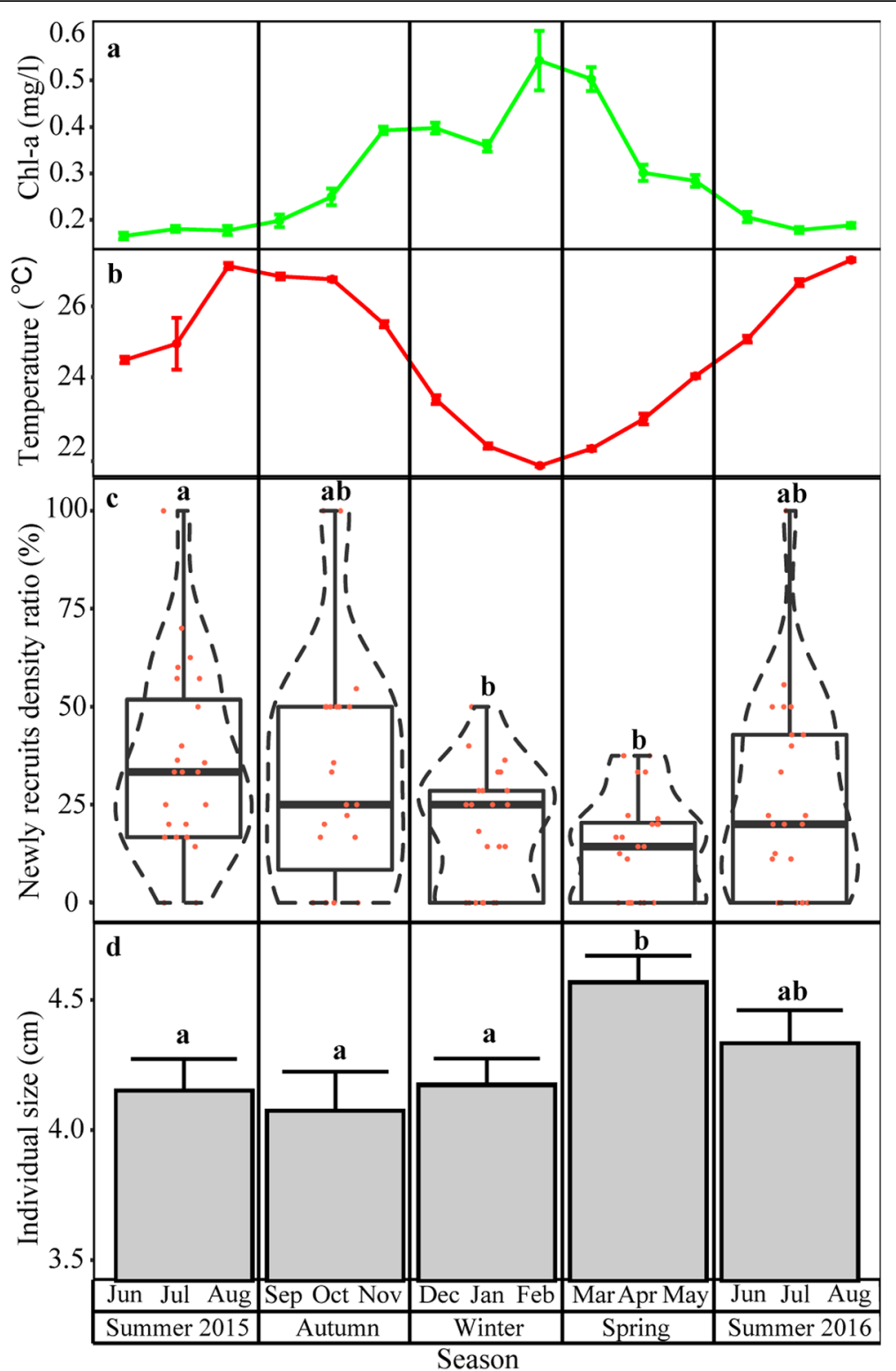

Fig. 2 Seasonal variation in P. mytiligera population structure in relation to chlorophyll- a concentration and sea temperature. a Variation in mean $( \pm$ SE) of chlorophyll- a concentration and $\mathbf{b}$ sea temperature in the Red Sea. $\mathbf{c}$ Violin plots display the proportion (\%) of P. mytiligera new recruit density in relation to total population density. The plot diameter reflects the probability density of new recruits for each season. Jittered points overlaid on boxplots represent individual samples. The bottom and top of the boxes represent the first and third quartiles, the central band represents the median, and whiskers represent 1.5 -fold the interquartile range. $\mathbf{d} P$. mytiligera seasonal average size in $\mathrm{cm}( \pm \mathrm{SE}$ ). Data averages were calculated from a unit of $15 \mathrm{~m}^{2}$ belt transect $(n=24$ belt transects per season). Different letters above bars indicate significant differences (permutational ANOVA, $p<0.05$ )

system, releasing gametes into the water column. Eggs were successfully fertilized and developed into swimming larvae, which then metamorphosed and developed into juveniles. Post-hatching stages were found during all 5 weeks of the experiment (Fig. 4). The mean survival percentage \pm SE of settled post-hatching stages for a oneweek period was $45.8 \% \pm 8 \%$ ( $n=27$ settlement plates, $n=$ 272 settled individuals).

\section{Gonad histological structure}

Histological sections were used to describe the P. mytiligera gonadal structure. P. mytiligera is characterized by multiple short hermaphrodite gonads (polycarps) embedded in the body wall [60]. Histological cross-sections of the body wall revealed that each polycarp comprises a testis composed of several follicles, and an ovary with several oocytes. The oocytes are on the opposite side of 


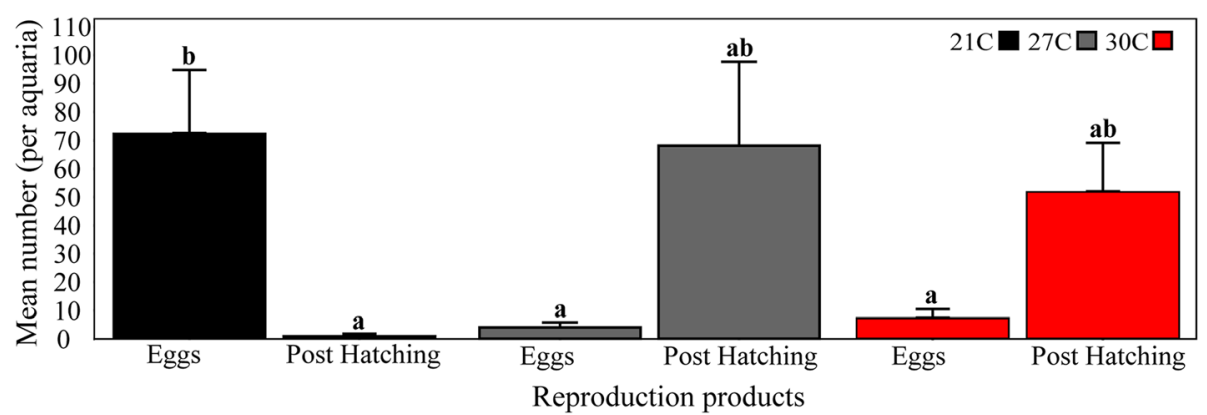

Fig. 3 P. mytiligera spawning productivity in an open water system under different temperature treatments. Mean number ( \pm SE) of $P$. mytiligera reproduction products (eggs and post hatching stages) under the three temperature treatments: cold $\left(21^{\circ} \mathrm{C}\right)$, heat $\left(30^{\circ} \mathrm{C}\right)$, and control $\left(27^{\circ} \mathrm{C}\right.$ ) throughout the six days of experiment ( $n=3$ aquaria/ treatment). Different letters above bars indicate significant differences between reproduction products of the same treatment (permutational ANOVA, $p<0.02$ )

the polycarp with respect to the testis and are grouped around a ciliated oviduct (Additional file 3).

\section{P. mytiligera developmental process}

The development process from the swimming larval stage to the juvenile stage was closely monitored and photographed at $25 \mathrm{C}^{\circ}$ for a period of 60 days (Figs. 5 and 6).

\section{Embryonic and larval development}

P. mytiligera releases its gametes into the water, where fertilization occurs. The eggs are brown in color and measure approximately $200 \mu \mathrm{m}$ in diameter. The

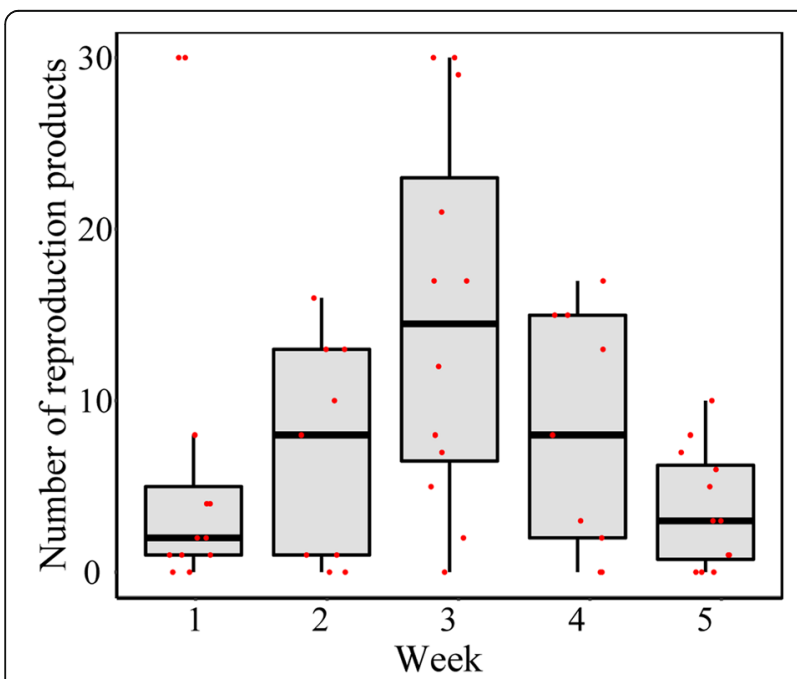

Fig. 4 Weekly variation in P. mytiligera spawning productivity in the closed water system. Weekly variation in $P$. mytiligera reproduction products throughout the five-week period ( $n=3$ aquaria). Jittered points overlaid on boxplots represent individual samples. The bottom and top of the boxes represent the first and third quartiles, the central band represents the median, and whiskers represent 1.5fold the interquartile range complete embryogenesis from fertilized egg to a swimming larva lasts $11 \mathrm{~h}$ at $25^{\circ} \mathrm{C}$ (Additional file 4). The larva, $1 \mathrm{~mm}$ long, is composed of an anterior trunk $(258 \pm 53 \mu \mathrm{m}, n=15)$ and a posterior tail (Fig. $5 \mathrm{a}-\mathrm{c})$. The trunk comprises the rudiment of the pharynx and the dorsal nervous system (Fig. 5b, g, h). The nervous system comprises a visceral ganglion, a sensory vesicle with a single pigmented sensory organ, and a hollow dorsal nerve cord extending posteriorly into the tail (Fig. 5f-i, Additional file 5). In the anterior trunk, three apical sensory adhesive papillae are discernible (Fig. 5b, e, i). The tail has a central notochord flanked by three paired bands of muscle cells (Fig. 5d, f). The nerve cord lies dorsal to the notochord (Figs. 5f-h). The larva's epidermis is covered by a double layer of tunic (Fig. 5b, f-g): the thick inner layer contains large brown/yellow cells; while the outer layer extends to form fins along the dorsal-ventral axis at the tail (Fig. 5f, g, j, l).

\section{Metamorphosis}

Following a swimming stage of about $12 \mathrm{~h}$, the larva adheres to the substrate with its papillae. The metamorphosis process begins with the absorption of the tail, the notochord, and the hollow dorsal nerve cord (Fig. 5j-l, Additional file 6). During this developmental phase, the trunk length increases from $125 \mu \mathrm{m}$ in the swimming larva to $300 \mu \mathrm{m}$ in a settled individual. The animal then loses all larval-specific structures of the body plan except the sensory vesicle and pharynx.

Following absorption of the tail (Fig. 5j, k), rotation of the body axis begins, and the animal reorganizes into the adult body plan (Fig. 6). The oral and atrial siphon rudiments appear in the first $48 \mathrm{~h}$ post-settlement (Fig. 6d, e). Both siphons are closed at this stage but are able to contract. Blood ampullae, joined through a blood vessel, elongate into the basal tunic that anchors the animal to the substrate (Fig. 6). On Day 3, the animal opens its siphons and enters the juvenile stage (Fig. 6f). 

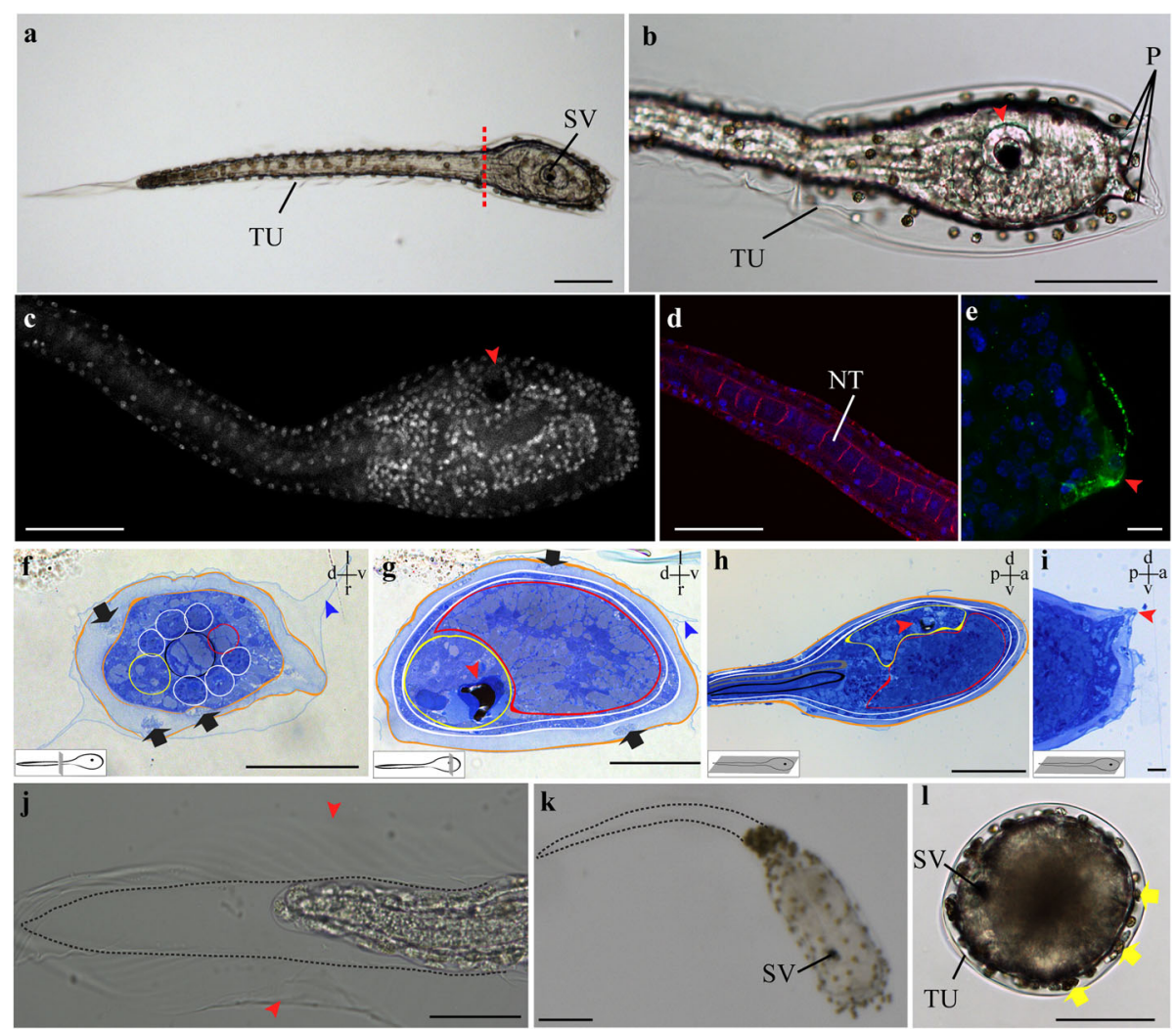

Fig. 5 Larval development and settlement in P. mytiligera. $\mathbf{a}-\mathbf{b}, \mathbf{j}$-I Light micrographs of live animals. c-e Confocal images. Larvae are labeled with three markers: phalloidin (red), anti-acetylated tubulin (green), and Hochest (blue/gray). $\mathbf{f}-\mathbf{i}$ Histological sections, Toluidine blue. $\mathbf{f}, \mathbf{g}$ cross-sections, $\mathbf{h}$, i sagittal sections. Section level and axis are shown in a scheme in the lower left corner and upper right corner of each histological image. All panels are anterior to the right unless otherwise indicated. $\mathbf{a}-\mathbf{i}$ swimming larva stage; $\mathbf{j}$-I metamorphosis. a Dashed line marks the boundary between the anterior trunk and posterior tail. b-c Larval trunk. Red arrowheads indicate the sensory vesicle. $\mathbf{d}$ Detail of larval tail. Note the notochord (NT) cells. e Detail of an anterior sensory papilla (red arrowhead). $\mathbf{f}$ Cross-section of larval tail showing notochord (black), endodermal strand (red), muscle strands (white), nerve cord (yellow), inner tunic layer (orange). Black arrows indicate tunic cells; blue arrowhead indicates the outer layer of tunic. g Cross-section of larval trunk showing pharynx (red), epidermis (white), visceral ganglion (yellow), and inner tunic layer (orange). Red arrowhead indicates the sensory vesicle, black arrows indicate tunic cells, blue arrowhead indicates the outer tunic layer. $\mathbf{h}$ Sagittal section of the larval anterior body showing notochord (black), nerve cord (gray), pharynx (red), visceral ganglion (yellow), epidermis (white), inner tunic layer (orange). Red arrows indicate the sensory vesicle. i Sagittal section of the larvae anterior sensory organs indicated by red arrows. $\mathbf{j}$ Detail of the resorbing tail in a metamorphosing individual. Red arrowheads indicate the outer layer of tunic, dashed line marks the original tail boundaries. $\mathbf{k}$ Settled larvae. Dashed line marks the original tail boundaries. I Top view of a larva immediately following adhesion. Yellow arrows indicate tunic cells. TU: tunic. Scale bar in A-D, H, K, L: $100 \mu \mathrm{m}$; in F, G, J: $50 \mu \mathrm{m}$; in E, I: $10 \mu \mathrm{m}$

\section{Juvenile development}

The juvenile presents the typical adult body plan (Fig. 6, Additional files 7, 8). Three days post- settlement the first two protostigmata are visible and active (Fig. $6 \mathrm{~g}$ ) and the heart begins to beat. Moving cells are visible in the blood vessels. Oral tentacles of the first order are recognizable at the base of the oral siphon (Fig. 6h). On Day 5, three protostigmata are visible and the endostyle can be distinguished in the ventral pharynx (Fig. 6i). On Day 7, the digestive system is differentiated, displaying the esophagus, stomach, and intestines (Fig. 6l, n, o, Additional file 8). The neural complex, now discernible, incorporates the cerebral ganglion and a neural gland with a single ciliated aperture in the pharynx (Fig. 6j, k, m, Additional file 8). On day 13, tentacles of the first and second order are visible in the oral siphon (Fig. 6j).

\section{Discussion}

A limited supply of animals is a major obstacle in the use of new model animals for experimental studies. In many cases, and especially in developmental studies, researchers depend on their model animal's natural reproduction period for the collection of mature adult specimens from the field to spawn in the lab. This limitation has forced researchers to focus on only a few well-established model animals. Our current study is thus important in presenting a culturing technique for a promising new model animal: the solitary ascidian Polycarpa mytiligera. 

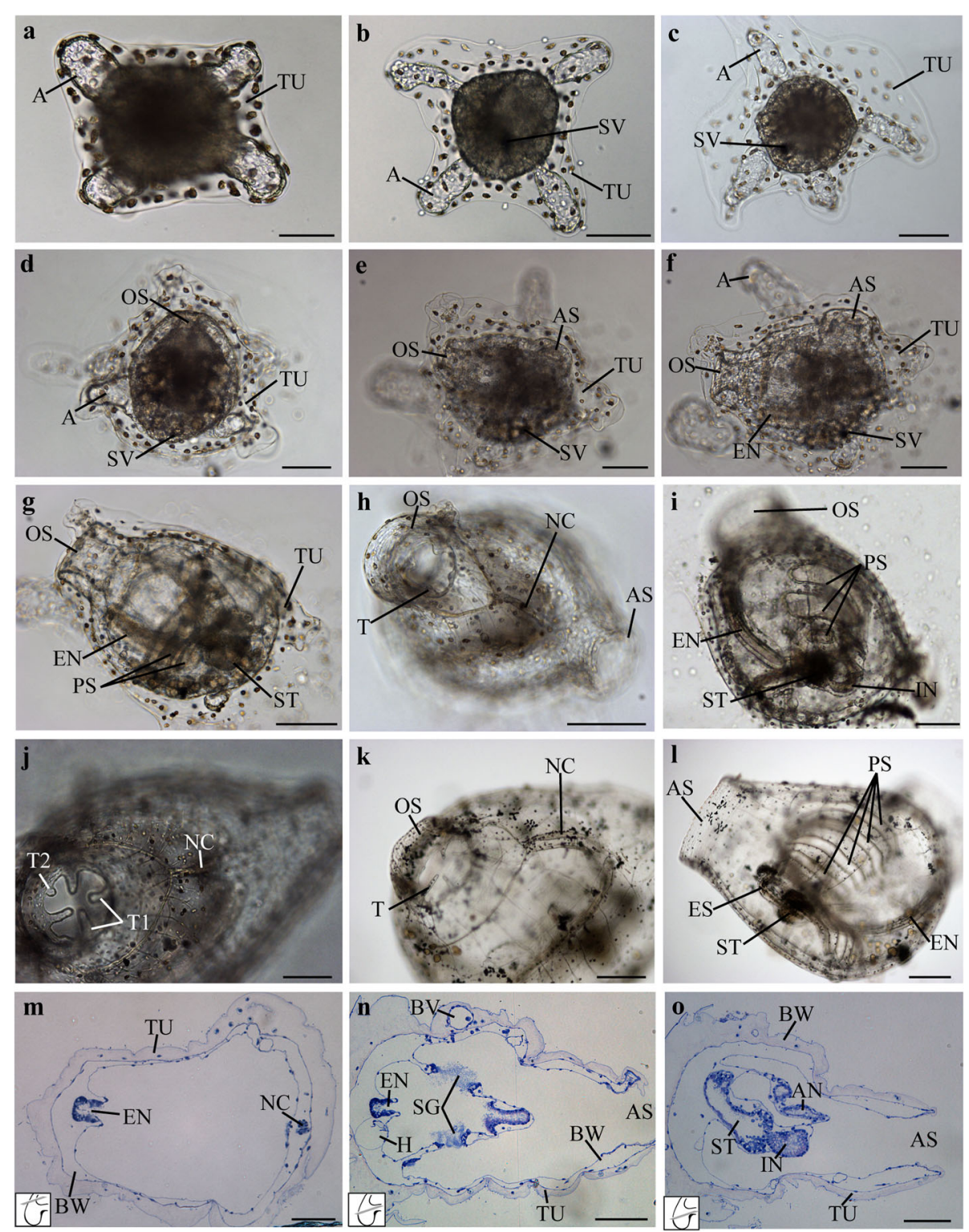

Fig. 6 Metamorphosis process and juvenile development in P. mytiligera. a-f Metamorphosis process and early juvenile development, light micrographs of live animals. a-e Body axis rotation stage. a $3 \mathrm{~h}, \mathbf{b} 11 \mathrm{~h}, \mathbf{c} 24 \mathrm{~h}, \mathbf{d} 33 \mathrm{~h}$, and e $45 \mathrm{~h}$ post-settlement. f Juvenile stage, $50 \mathrm{~h}$ postsettlement. g-o Juvenile development. $\mathbf{g - I}$ Light micrographs of live animals. Anterior at top. $\mathbf{m}$-o Histological cross-section, 7 days postsettlement. Scheme of the section level is shown in the lower left corner of each image. Ventral at left. $\mathbf{g}-\mathbf{h} 3$ days post-settlement: $\mathbf{g} 58 \mathrm{~h}$ and $\mathbf{h}$ $70 \mathrm{~h}$ post-settlement. $\mathbf{i} 5$ days post-settlement. $\mathbf{j} 13$ days post-settlement. $\mathbf{k}-\mathbf{I} 58$ days post-settlement. Ampulla (A), atrial siphon (AS), anus (AN), tunic blood vessel (BV), body wall (BW), digestive system (DS), endostyle (EN), esophagus (ES), heart (H), neural complex (NC), oral siphon (OS), pigmented sensory organ (SO), protostigmata (PS), stomach (ST), tunic (TU) and tentacles (T1 first order, T2 second order). Scale bar in A-K: $100 \mu \mathrm{m}$; in L: $200 \mu \mathrm{m}$; in M-O: $50 \mu \mathrm{m}$

\section{P. mytiligera's natural reproductive cycle exhibits seasonal fluctuation}

The seasonal variation in population density and in body size observed in P. mytiligera population in the field, based on 18 months of surveys, suggests that this species' recruitment period starts in the summer and ends with the onset of winter.
Water temperature has been found to have an important influence on the growth and reproduction cycles of ascidians [30, 34, 61] as well as on their recruitment [62-64]. Increased water temperature in the summer induces spawning in $P$. mytiligera, resulting in a higher density of new recruits during this season in comparison to the winter and spring. 
In the autumn the average size of individuals was at its lowest, due to the settlement of new recruits and the mortality of adults (the latter may be related to the decline in food availability and the drop in water temperature) $[65,66]$. A relationship between mortality and low temperature was also found in the colonial ascidians Botryllus eilatensis from the Red Sea [67] and Botryllus schlosseri and Botrylloides violaceus in British Colombia [68], where low temperature had a negative effect on colony size and survival. Larger individuals were found in the spring, following the vertical mixing event $[65,66]$, as food availability was then maximal.

The results from the open water system spawning experiment support our hypothesis of the summer and autumn as $P$. mytiligera's natural reproduction seasons. During the summer and autumn gametes and larvae were found in both the control and the high temperature treatment, indicating that reproduction can be easily obtained with no external induction required during this time of the year. No reproduction products were found during the winter and the following spring in both the high temperature and the control treatments. These findings imply that $P$. mytiligera gonads are not mature during winter and were therefore unable to undergo spawning despite the thermal shock treatment. Previous studies have shown that ascidian spawning events are affected by both food availability and water temperature [32-35]. Since chlorophyll concentration is comparatively high in the Gulf waters during winter and spring, $P$. mytiligera reproduction was probably inhibited by other parameters, such as low water temperature and shorter day length, which were not yet optimal for spawning. It is therefore possible that during winter and spring the mature animals need to acquire the energy necessary for gonad development towards the summer season, when water temperature rises to a level that allows their reproduction. A similar reproduction cycle was found in other ascidian species from the Red Sea. The colonial ascidian Botryllus eilatensis and the solitary ascidian Halocynthia spinosa, both native to the Red Sea, display a seasonal reproduction period that correlates with the summer $[39,69]$.

The prominent effect of temperature on $P$. mytiligera spawning was demonstrated in our low temperature experiment. While cold temperature did not prevent spawning and the release of a high number of eggs during the natural reproduction period, it did affect their further development into larvae and juveniles. The negative effect of low temperature on fertilization and development in P. mytiligera further supports the inability of this species to reproduce during the winter. Similar results were achieved by Batty et al. [70], showing that low temperature had a negative effect on the development and survival of the ascidian larva Dendrodoa grossularia.
Elevating water temperature above the natural summer conditions was shown here to have no significant effect on spawning, fertilization, or development, and should therefore be excluded from the culturing protocol of $P$. mytiligera.

\section{Artificial spawning can be obtained year-round, independent of the natural reproductive season}

The current study has demonstrated that $P$. mytiligera adults can be induced to spawn at any given time throughout the year, enabling a constant supply of reproduction products for long-term experiments. A gradual experimental shift in water temperature and day length led to spawning events taking place outside of this species' natural reproduction period. During this experiment, water temperature and day length were artificially and gradually altered from winter/spring conditions to summer conditions, resulting in spawning success for the experimental animals, but not for the control, which had maintained the natural winter/spring conditions. Furthermore, the spawning events were followed by successful larval development and metamorphosis into settled juveniles, indicating the high quality of the released gametes. The current protocol utilizes the animal's natural spawning behavior in order to collect gametes, as in-vitro fertilization results in low fertilization success due to the gonads' small size and difficulty in discerning and dissecting the genital ducts. Although in-vitro fertilization is better controlled, offering an advantage for screening for developmental mutations and transgenic lines, the collection of gametes by natural spawning enables the adults to be kept for repeated spawning and for further genetic studies $[5,15]$.

\section{P. mytiligera as a promising model for comparative developmental studies}

The introduction of $P$. mytiligera adults into artificial conditions in order to induce spawning was highly successful, with $100 \%$ survival in all treatments. Adult animals exhibited repeated spawning events during the 5 weeks of the experiment. Furthermore, gamete release was followed by successful fertilization and development into larvae, which metamorphosed into settled juveniles that continued to develop under the artificial conditions. The average number of reproduction products found in our aquaria was lower than those reported for other solitary species, used in large-scale culturing systems [5, 15]. Nevertheless, it is important to note that the current experiment used the minimum possible number of adults per aquarium, and it is probable that increasing the aquarium size and the number of adults per aquarium will result in a higher number of reproduction products.

The ability to successfully culture $P$. mytiligera in a closed system has great advantages for facilities with low 
or no access to the sea, or for genetic experiments in which separating the experimental animals from the natural population is of significance.

The ascidians phylogenetic position makes them a valuable model for addressing questions of chordate development and evolution [1, 6, 71]. Comparative studies have revealed that some of their developmental processes and gene signaling pathways are shared with vertebrates. For example, analysis of notochord development in $C$. intestinalis has provided valuable information on the evolution of the vertebrate form $[7,13,71,72]$. The current study presents the first description of $P$. mytiligera's developmental and morphological traits and provides a basis for future experimental comparative studies utilizing this species. Previous studies have revealed several modes of reproduction strategies in the genus Polycarpa. The species $P$. cryptocarpa kroboja found in northern Taiwan is oviparous and produces large eggs of 150 $240 \mu \mathrm{m}$ [26], while the species $P$. tinctoron from Australia is viviparous and retains its embryos in the peribranchial cavities until they are at the stage of advanced oozooids [25]. Our present findings indicate that $P$. mytiligera is oviparous, producing eggs of $200 \mu \mathrm{m}$ in diameter. In captivity, fertilization of this species occurs during the twilight hours, and earlystage embryos can be collected at this time. Following the embryogenesis process a swimming larva hatches, featuring a typical simple body plan, similar to that in other solitary species [42]. Based on histological sections, we report that the sensory vesicle contains a single pigmented sensory, the statocyte, a unicellular organ used as a gravity receptor required for the swimming behavior [73, 74]. While in other solitary species, such as Ciona robusta and Halocynthia roretzi, a second sensory organ, the ocellus (responsible for light sensing) has been described [75-77], in $P$. mytiligera larvae only a single sense receptor was found. A single pigmented sensory organ was previously described for larvae of other Polycarpa species $[27,78]$ and for other Styelidae, such as the colonial species Botryllus schlosseri, in which a single organ, called a photolith, was described and is believed to be able to sense both gravity and light [79]. It remains to be established whether Polycarpa larvae also possess a single photolith or, rather, whether the ability to sense light has been lost in these larvae.

$P$. mytiligera's development timeline was found to resemble that of other oviparous solitary species, such as C. robusta and S. plicata [44,80-82]. The larvae initiate settlement and metamorphosis within about $12 \mathrm{~h}$ posthatching. Three days following settlement the animal contracts its oral siphons and two protostigmata appear as it begins to feed. At this point, it has reached the juvenile stage. This life cycle coincides with that of C. robusta, which also opens its siphons and features the first two protostigmata 3 days post-hatching [44]; and with Styela, which develops into a juvenile with functional siphons $69-70 \mathrm{~h}$ post-hatching [80-82]. In the weeks that follow the animal increases in size and the ampules extend and spread over the substrate. Blood flow can be clearly seen in these extensions, as previously reported for the solitary ascidian S. plicata [83].

In their first few months of life $P$. mytiligera juveniles are transparent, enabling clear visualization of the morphological structure and developmental process that take place during these early life stages, and offering a great advantage for experimental developmental studies.

\section{Conclusions}

With $P$. mytiligera presenting a promising model system for regenerative studies, understanding its reproduction and developmental processes and establishing appropriate culturing methods are crucial steps in rendering this species an applicable model system.

Here we provide protocols for the maintenance and spawning of adults and the rearing of larvae in an open system that utilizes fresh seawater, as well as in an artificial seawater system. P. mytiligera exhibits a rapid development process, with larvae initiating settlement and metamorphosis within about $12 \mathrm{~h}$ post-hatching. Metamorphosis into juveniles, featuring the adult body plan, was observed 3 days following settlement.

Culturing new generations in the laboratory offers the opportunity to perform controlled comparative experiments using individual animals at any stage of their life cycle, and facilitates the development of genetic and molecular tools, providing unique insights into specific developmental processes. The findings from the current study thus have important implications for future research on $P$. mytiligera as a new model for developmental and regenerative studies.

\section{Supplementary information}

Supplementary information accompanies this paper at https://doi.org/10. 1186/s12983-020-00365-x.

Additional file 1: Table 1. Sample size and environmental condition at the collection site and in system A.

Additional file 2: Figure S1. P. mytiligera seasonal average number $/ \mathrm{m}^{2}$ $( \pm \mathrm{SE})$.

Additional file 3: Figure S2. P. mytiligara gonad stracture. Additional file 4: Movie 1. Time lapse of $P$. mytiligera embryogenesis process.

Additional file 5: Figure S3. Histological sections of $P$. mytiligera larvae showing the connection between the nervous system components.

Additional file 6: Movie 2. Time lapse of $P$. mytiligera larvae tail absorption process. 
Additional file 7: Movie 3. P. mytiligera 13-day old juvenile showing the different body structure and organs. Scale bar: 100 $\mu \mathrm{m}$.

Additional file 8: Figure S4. Morphology of $P$. mytiligera juvenile stage.

\section{Acknowledgements}

We would like to thank N. Paz for editorial assistance. We would like to acknowledge the Inter-University Institute (IUI) and the National Center for Mariculture in Eilat and their staff for their ongoing support and the use of their facilities. Special thanks are due to N. Gordon for her help with the larval rearing and microscopy images and movies. We thank Dr. F. Gasparini, Dr. A. Voskoboynik, and the Shenkar lab members for their support and advice.

\section{Authors' contributions}

TG located and collected the animals, established the methods for animal spawning and larval rearing, raised the larvae, performed the temperature and spawning experiments, as well as the immunocytochemistry, light and confocal microscopy, drew the figures, carried out the statistical analysis, and drafted the manuscript. LR participated in larval collection and rearing. TG and FC prepared the histology sections. TG and LM analyzed the histological sections and microscope images and described the development process. TG, LM, and NS jointly conceived and supervised the study and interpreted the data. All authors read and approved the final manuscript.

\section{Funding}

Funding was provided by: The Yitzhak Navon PhD scholarship to TG, The Erasmus Plus scholarships and the COST (European Cooperation in Science and Technology) Short Term Scientific Mission (COST Action MARISTEM - CA 16203) to TG which allowed a collaborative research between Tel Aviv University and the University of Padova, PRIN - Prot. 2015NSFHXF to LM.

\section{Availability of data and materials}

The datasets used and/or analyzed during the current study are available from the corresponding author upon reasonable request.

\section{Ethics approval and consent to participate}

Not applicable.

\section{Consent for publication}

Not applicable.

\section{Competing interests}

The authors declare that they have no competing interests.

\section{Author details}

${ }^{1}$ George S. Wise Faculty of Life Sciences, School of Zoology, Tel-Aviv University, 6997801 Tel-Aviv, Israel. ${ }^{2}$ Department of Biology, University of Padova, 35121 Padova, Italy. ${ }^{3}$ The Steinhardt Museum of Natural History, Israel National Center for Biodiversity Studies, Tel-Aviv University, 6997801 Tel-Aviv, Israel.

\section{Received: 20 March 2020 Accepted: 21 May 2020}

Published online: 11 June 2020

\section{References}

1. Delsuc F, Brinkmann H, Chourrout D, Philippe $H$. Tunicates and not cephalochordates are the closest living relatives of vertebrates. Nature. 2006; 439:965-8.

2. Delsuc F, Tsagkogeorga G, Lartillot N, Philippe H. Additional molecular support for the new chordate phylogeny. Genesis. 2008:46:592-604

3. Millar RH. The biology of ascidians. Adv Mar Biol. 1971;9:1-100.

4. Millar $\mathrm{RH}$. The annual growth and reproductive cycle in four ascidians. J Mar Biol Assoc U K. 1952:31:41-61.

5. Joly JS, Kano S, Matsuoka T, Auger H, Hirayama K, Satoh N, et al. Culture of Ciona intestinalis in closed systems. Dev Dyn. 2007:236:1832-40.

6. Delsuc F, Philippe H, Tsagkogeorga G, Simion P, Tilak MK, Turon X, et al. A phylogenomic framework and timescale for comparative studies of tunicates. BMC Biol. 2018;16:39.

7. Satoh N. A deep dive into the development of sea squirts. Nature. 2019;571: 333-4.
8. Jeffery WR. Closing the wounds: one hundred and twenty five years of regenerative biology in the ascidian Ciona intestinalis. Genesis. 2015;53: 48-65.

9. Voskoboynik A, Weissman IL. Botryllus schlosseri, an emerging model for the study of aging, stem cells, and mechanisms of regeneration. Invertebr Reprod Dev. 2015:59:33-8.

10. Kassmer SH, Nourizadeh S, De Tomaso AW. Cellular and molecular mechanisms of regeneration in colonial and solitary ascidians. Dev Biol. 2019:448:271-8

11. Feinberg S, Roure A, Piron J, Darras S. Antero-posterior ectoderm patterning by canonical Wnt signaling during ascidian development. PLoS Genet. 2019; 15:1-25.

12. Stolfi A, Christiaen L. Genetic and genomic toolbox of the chordate Ciona intestinalis. Genetics. 2012;192:55-66.

13. Passamaneck YJ, Di Gregorio A. Ciona intestinalis: chordate development made simple. Dev Dyn. 2005;233:1-19.

14. Brunetti R, Gissi C, Pennati R, Caicci F, Gasparini F, Manni L. Morphological evidence that the molecularly determined Ciona intestinalis type a and type $B$ are different species: Ciona robusta and Ciona intestinalis. J Zool Syst Evol Res. 2015;53:186-93.

15. Hendrickson C, Christiaen L, Deschet K, Jiang D, Joly JS, Legendre L, et al. Culture of adult ascidians and ascidian genetics. In: Ettensohn CA, Wray GA, Wessel GM, editors. Dev Sea Urchins, Ascidians, Other Invertebr Deuterostomes Exp Approaches. San Diego: Academic; 2004. p. 143-70.

16. Lambert G, Karney R, Rhee W, Carman M. Wild and cultured edible tunicates: a review. Manag Biol Invasions. 2016;7:59-66.

17. Lee YJ, Wilberg MJ, Han E, Choi KS, Lee WC, Kang CK. Growth of the longline-cultured sea squirt Halocynthia roretzi in a temperate bay of Korea: biochemical composition and physiological energetics. Aquaculture. 2020; $516: 734526$

18. Koplovitz G, Shenkar N. The biodiversity of the class Ascidiacea in the Gulf of Eilat (Aqaba ) [Internet]. Isr Taxon Initiat Rep. 2014:1-18 Available from: http://taxonomy.tau.ac.l//eng/content/biodiversity-survey-results.

19. Shenkar N, Gordon T. Gut-spilling in chordates: evisceration in the tropical ascidian Polycarpa mytiligera. Sci rep. 2015;5:9614.

20. Gordon T, Shenkar N. Solitary ascidians as model organisms in regenerative biology studies. In: Kloc M, Kubiak J, editors. Mar Org as Model Syst Biol Med Results Probl Cell Differ. Cham: Springer; 2018. p. 321-36.

21. Gordon T, Manni L, Shenkar N. Regeneration ability in four stolidobranch ascidians: ecological and evolutionary implications. J Exp Mar Bio Ecol. 2019; 519:151184

22. Monniot C. Ascidies de Nouvelle-Calédonie II . Les genres Polycarpa et Polyandrocarpa. Bull du Muséum Natl d'histoire Nat. 1987:9:275-310.

23. Monniot C, Monniot F, Laboute P. Coral reef ascidians of New Caledonia. Paris: ORSTOM; 1991

24. Pérez-Portela R, Bishop JDD, Davis AR, Turon X. Phylogeny of the families Pyuridae and Styelidae (Stolidobranchiata, Ascidiacea) inferred from mitochondrial and nuclear DNA sequences. Mol Phylogenet Evol. 2009;50: 560-70.

25. Millar BRH. The breeding and development of the ascidian Polycarpa tinctor. J Cell Sci. 1962:3:399-403.

26. Chen YT, Dai CF. Sexual reproduction of the ascidian Polycarpa cryptocarpa kroboja from the northern coast of Taiwan. Acta Oceanogr Taiwanica. 1998; 37:201-10.

27. Kott P. The Australian ascidiacea. Part 1: phlebobranchiata and stolidobranchiata. Mem Queensl Mus. 1985;23:1-440.

28. Mackie GO, Burighel P. The nervous system in adult tunicates: current research directions. Can J Zool. 2005:83:151-83.

29. Dahlberg C, Auger H, Dupont S, Sasakura Y, Thorndyke M, Joly JS. Refining the Ciona intestinalis model of central nervous system regeneration. PLoS One. 2009;4:e4458

30. Lambert G. Ecology and natural history of the protochordates. Can J Zool. 2005;83:34-50.

31. Lambert CC. Historical introduction, overview, and reproductive biology of the protochordates. Can J Zool. 2005;83:1-7.

32. Goodbody I. Continuous breeding in three species of tropical ascidian. Proc Zool Soc London. 1961;136:403-9.

33. Lambert CC, Brandt CL. The effect of light on the spawning of Ciona intestinalis. Biol Bull. 1967;132:222-8.

34. Yamaguchi M. Growth and reproductive cycles of the marine fouling ascidians Ciona intestinalis, Styela plicata, Botrylloides violaceus, and 
Leptoclinum mitsukurii at Aburatsubo-Moroiso inlet (Central Japan). Mar Biol. 1975;29:253-9

35. Lambert CC, Lambert G. Persistence and differential distribution of nonindigenous ascidians in harbors of the Southern California bight. Mar Ecol Prog Ser. 2003;259:145-61.

36. Lambert $\mathrm{G}$. The general ecology and growth of a solitary ascidian, Corella willmeriana. Biol Bull. 1968;135:296-307.

37. Lambert CC, Lambert IM, Lambert G. Brooding strategies in solitary ascidians: Corella species from north and south temperate waters. Can J Zool. 1995;73:1666-71 NRC Research Press.

38. Fletcher LM, Forrest BM, Bell JJ. Natural dispersal mechanisms and dispersal potential of the invasive ascidian Didemnum vexillum. Biol Invasions. 2013; 15:627-43.

39. Shenkar N, Zeldman $Y$, Loya $Y$. Ascidian recruitment patterns on an artificial reef in Eilat (Red Sea). Biofouling. 2008;24:119-28.

40. Astudillo JC, Leung KMY, Bonebrake TC. Seasonal heterogeneity provides a niche opportunity for ascidian invasion in subtropical marine communities. Mar Environ Res. 2016;122:1-10

41. Ma KCK, Deibel D, Ben LJ, McKenzie CH. Spatio-temporal dynamics of ascidian larval recruitment and colony abundance in a non-indigenous Newfoundland population. Mar Ecol Prog Ser. 2017:585:99-112.

42. Cloney RA. Ascidian larvae and the events of metamorphosis. Integr Comp Biol. 1982;22:817-26.

43. Davidson B, Swalla BJ. A molecular analysis of ascidian metamorphosis reveals activation of an innate immune response. Development. 2002;129: 4739-51.

44. Chiba S, Sasaki A, Nakayama A, Takamura K, Satoh N. Development of Ciona intestinalis juveniles (through 2nd ascidian stage). Zool Sci. 2004;21:285-98.

45. Karaiskou A, Swalla BJ, Sasakura Y, Chambon JP. Metamorphosis in solitary ascidians. Genesis. 2015:53:34-47.

46. Loya Y. Plotless and transect methods. Coral Reefs Res Methods. Paris: UNESCO; 1978. p. 197-218.

47. Hill J, Wilkinson C. Methods for ecological monitoring of coral reefs. Aust Inst Mar Sci Townsv. 2004;117. Available from: https://www.cbd.int/doc/ casestudies/tttc/tttc-00197-en.pdf.

48. Shaked $Y$, Genin A. The Israel national monitoring program at the Gulf of Eilat [Internet]. Available from: https://iui-eilat.huji.ac.il/Research/ NMPMeteoData.aspx..

49. Miguel M. Giant clam aquaculture: a review on induced spawning and larval rearing. Int J Mar Sci. 2012:2:62-9.

50. Battaglene SC, Seymour JE, Ramofafia C, Lane I. Spawning induction of three tropical sea cucumbers, Holothuria scabra, H. fuscogilva and Actinopyga mauritiana. Aquaculture. 2002;207:29-47.

51. Theodosiou M, Colin A, Schulz J, Laudet V, Peyrieras N, Nicolas JF, et al. Amphioxus spawning behavior in an artificial seawater facility. J Exp Zool Part B Mol Dev Evol. 2011;316(B):263-75.

52. Gaudette MF, Lowther JL, Pechenik JA. Heat shock induces metamorphosis in the larvae of the prosobranch gastropod Crepidula fornicata. J Exp Mar Bio Ecol. 2001;266:151-64.

53. Rivetti I, Fraschetti S, Lionello P, Zambianchi E, Boero F. Global warming and mass mortalities of benthic invertebrates in the Mediterranean Sea. PLoS One. 2014;9:1-22.

54. Pennati R, Dell'Anna A, Zega G, de Bernardi F. Immunohistochemical study of the nervous system of the tunicate Thalia democratica (forsskal, 1775). Eur J Histochem. 2012;56:96-101.

55. Braun K, Stach T. Comparative study of serotonin-like immunoreactivity in the branchial basket, digestive tract, and nervous system in tunicates. Zoomorphology. 2016;135:351-66.

56. Valero-Gracia A, Marino R, Crocetta F, Nittoli V, Tiozzo S, Sordino P. Comparative localization of serotonin-like immunoreactive cells in Thaliacea informs tunicate phylogeny. Front Zool. 2016;13:45

57. Jeffery WR. Progenitor targeting by adult stem cells in Ciona homeostasis, injury, and regeneration. Dev Biol. 2019;448:279-90.

58. Hervé M. RVAideMemoire: diverse basic statistical and graphical functions. R Packag. version 0.9-50; 2015.

59. Kim Kl, van de Wiel MA. Effects of dependence in high-dimensional multiple testing problems. BMC Bioinformatics. 2008;9:1-12.

60. Gordon T. Ecology and biology of the solitary ascidian Polycarpa mytiligera in the Red Sea. Israel: Tel Aviv University; 2016.

61. Bourque D, Davidson J, MacNair NG, Arsenault G, LeBlanc AR, Landry T, et al. Reproduction and early life history of an invasive ascidian Styela clava
Herdman in Prince Edward Island, Canada. J Exp Mar Bio Ecol. 2007;342:7884.

62. Osman RW, Whitlatch RB. Variation in the ability of Didemnum sp. to invade established communities. J Exp Mar Bio Ecol. 2007;342:40-53.

63. Auker LA, Oviatt CA. Factors influencing the recruitment and abundance of Didemnum in Narragansett Bay, Rhode Island. ICES J Mar Sci. 2008;65:765-9.

64. Valentine PC, Carman MR, Dijkstra J, Blackwood DS. Larval recruitment of the invasive colonial ascidian Didemnum vexillum, seasonal water temperatures in New England coastal and offshore waters, and implications for spread of the species. Aquat Invasions. 2009;4:153-68.

65. Genin A, Lazar B, Brenner S. Vertical mixing and coral death in the Red Sea following the eruption of mount Pinatubo. Nature. 1995;377:507-10.

66. Zarubin M, Lindemann Y, Genin A. The dispersion-confinement mechanism: phytoplankton dynamics and the spring bloom in a deeply-mixing subtropical sea. Prog Oceanogr. 2017;155:13-27.

67. Shenkar N, Bronstein O, Loya Y. Population dynamics of a coral reef ascidian in a deteriorating environment. Mar Ecol Prog Ser. 2008;367:163-71.

68. Epelbaum A, Herborg LM, Therriault TW, Pearce CM. Temperature and salinity effects on growth, survival, reproduction, and potential distribution of two non-indigenous botryllid ascidians in British Columbia. J Exp Mar Bio Ecol. 2009;369:43-52 Elsevier B.V. Available from: https://doi.org/10.1016/j. jembe.2008.10.028.

69. Shmuel Y, Shenkar N. Reproductive cycle and ecology of the tropical ascidian Halocynthia spinosa in the Red Sea. Mar Biol. 2017;164:1-12.

70. Batty RS, Blaxter JHS, Bone Q. The effect of temperature on the swimming of a teleost (Clupea harengus) and an ascidian larva (Dendrodoa grossularia). Comp Biochem Physiol Part A Physiol. 1991;100:297-300.

71. Satoh $\mathrm{N}$. The ascidian tadpole larva: comparative molecular development and genomics. Nat Rev Genet. 2003;4:285-95.

72. Diogo R, Kelly RG, Christiaen L, Levine M, Ziermann JM, Molnar JL, et al. A new heart for a new head in vertebrate cardiopharyngeal evolution. Nature. 2015;520:466-73.

73. Tsuda M, Sakurai D, Goda M. Direct evidence for the role of pigment cells in the brain of ascidian larvae by laser ablation. J Exp Biol. 2003;206:1409-17.

74. Jiang D, Tresser JW, Horie T, Tsuda M, Smith WC. Pigmentation in the sensory organs of the ascidian larva is essential for normal behavior. J Exp Biol. 2005;208:433-8.

75. Ohtsuki H. Statocyte and ocellar pigment cell in embryos and larvae of the ascidian, Styela plicata (Lesueur): statocyte/ocellus/ascidian/embryo/larva. Develop Growth Differ. 1990;32:85-90

76. Esposito R, Racioppi C, Pezzotti MR, Branno M, Locascio A, Ristoratore F, et al. The ascidian pigmented sensory organs: structures and developmental programs. Genesis. 2015;53:15-33.

77. Hudson C. The central nervous system of ascidian larvae. Wiley Interdiscip Rev Dev Biol. 2016;5:538-61.

78. Berrill NJ. The gonads, larvae, and budding of the polystyelid ascidians Stolonica and Distomus. J Mar Biol Assoc U K. 1948;27:633-50.

79. Sorrentino M, Manni L, Lane NJ, Burighel P. Evolution of cerebral vesicles and their sensory organs in an ascidian larva. Acta Zool. 2000;81:243-58.

80. Huang Y, Ke C, Feng D, Zhou S, Li F. Observations on the morphology of embryonic and larval development in Styela canopus Savigny. Acta Oceanol Sin. 2003;22:621-8.

81. Thiyagarajan V, Qian PY. Effect of temperature, salinity and delayed attachment on development of the solitary ascidian Styela plicata (Lesueur). J Exp Mar Bio Ecol. 2003;290:133-46.

82. Feng D, Ke C, Lu C, Li S. The influence of temperature and light on larval pre-settlement metamorphosis: a study of the effects of environmental factors on pre-settlement metamorphosis of the solitary ascidian Styela canopus. Mar Freshw Behav Physiol. 2010;43:11-24.

83. Jiménez-Merino J, Santos de Abreu I, Hiebert LS, Allodi S, Tiozzo S, De Barros CM, et al. Putative stem cells in the hemolymph and in the intestinal submucosa of the solitary ascidian Styela plicata. Evodevo. 2019;10:31.

\section{Publisher's Note}

Springer Nature remains neutral with regard to jurisdictional claims in published maps and institutional affiliations. 